\title{
Steady State Levels of Dehydrogenases and $\alpha$ - and $\beta$-Glucosidases in Klebsiella aerogenes
}

\author{
By A. C. R. DEAN AND P. J. RODGERS \\ Physical Chemistry Laboratory, University of Oxford
}

(Accepted for publication 26 March 1969)

\begin{abstract}
SUMMARY
Klebsiella (Aerobacter) aerogenes (NCIB 418, Bacterium aerogenes no. 240) was grown at dilution rates between $0 . \mathrm{I}$ and $\mathrm{I} \cdot 0 \mathrm{hr}^{-1}$ in a variety of nutrientlimited chemostats and the activities of dehydrogenases, particularly glucose $\left(R_{G}\right)$, fructose $\left(R_{F}\right)$, sucrose $\left(R_{S}\right)$, maltose $\left(R_{M}\right)$ and gluconate $\left(R_{G N}\right)$ dehydrogenases, were determined in intact organisms. Their activities varied from system to system, but, with a few exceptions, were largely independent of the dilution rate. $R_{a}$ was generally high when sugars provided the carbon for growth but when intermediates of the tricarboxylic acid cycle were used it was often low. $R_{o x}$ behaved like $R_{G}$ but $R_{F}, R_{s}$, and $R_{M}$ were more variable. In general the activities were higher in C-limitation than in other nutrient-limited conditions.

Specific activities of $\alpha$ - and $\beta$-glucosidase were also determined in some of the systems. Organisms grown in a maltose-limited system had the highest $\alpha$-glucosidase activity but $40 \%$ of this level was observed in those from a cellobiose-limited system although cellobiose is a $\beta$-glucoside. Glucose, fructose, sucrose, lactose or disaccharides containing an $\alpha \mathrm{I} \rightarrow 6$ linkage as carbon sources induced little activity. As expected, growth in cellobiose-limited conditions led to high $\beta$-glucosidase activity but melibiosegrown cells were about $50 \%$ as active. Replacing $\mathrm{NH}_{4}{ }^{+}$, the usual $\mathrm{N}$ source in the medium, by $\mathrm{NO}_{2}{ }^{-}$in a glucose-limited system increased the $\beta$-glucosidase activity five- to sixfold, while $\mathrm{NO}_{3}{ }^{-}$led to a tenfold decrease. $\alpha$-Glucosidase was less affected.
\end{abstract}

\section{INTRODUCTION}

Although their need has been pointed out (Pirt, 1967; Málek, 1969) relatively few studies have appeared on the activities of enzymes in bacteria growing in the steady state of continuous culture. Those which have, however, indicate the usefulness of the approach (see for example Tempest \& Herbert, 1965; Wright \& Lockhart, 1965; Hamlin, Ng \& Dawes, 1967; Clarke, Houldsworth \& Lilly, 1968), since if the chemostat technique is used the effect of changes in the dilution (growth) rate and the nature of the rate-limiting nutrient in the medium can be assessed. In this paper the effect of these variables on the steady state specific activities of some dehydrogenase systems in Klebsiella (Aerobacter) aerogenes ( $\mathrm{NClB} 418$, Bacterium aerogenes strain no. 240), particularly those acting on glucose, gluconate, fructose, maltose and sucrose is assessed. The $\alpha$ - and $\beta$-glucosidase activity of the cells is also examined although in less detail. 


\section{METHODS}

The continuous culture apparatus and the general experimental techniques have been described elsewhere (Dean \& Rogers, 1967). The standard salts glucose medium contained (g./l.): $\mathrm{FeSO}_{4} .7 \mathrm{H}_{2} \mathrm{O}, 0.2 \times 10^{-3} ; \mathrm{MgSO} .7 \mathrm{H}_{2} \mathrm{O}, 0.039 ;\left(\mathrm{NH}_{4}\right)_{2} \mathrm{SO}_{4}, 0.96$; $\mathrm{KH}_{2} \mathrm{PO}_{4}$, I. I4; $\mathrm{Na}_{2} \mathrm{HPO}_{4}$. I2 $\mathrm{H}_{2} \mathrm{O}, 6 \cdot 13$; glucose, $19 \cdot 2 ; \mathrm{pH} 7 \cdot \mathrm{I}$. For chemostat operation the concentration of the rate-limiting nutrient was reduced to a level which gave a steady state cell mass in the culture vessel of $0.12 \mathrm{mg}$. dry weight $/ \mathrm{ml}$. over as wide a range of dilution rates as possible. In $\mathrm{C}$-limited conditions this was $300 \mathrm{mg}$. $/ \mathrm{l}$. when sugars and related substances were the carbon sources and I g./l. when intermediates of the tricarboxylic acid cycle and related substances were used. $\mathrm{NH}_{4}^{+}, \mathrm{K}^{+}, \mathrm{Mg}^{2+}$, $\mathrm{SO}_{4}{ }^{2-}$ and $\mathrm{PO}_{4}{ }^{3-}$-limited systems contained respectively $27 \cdot 3,2 \cdot 0,0 \cdot 35, \mathrm{I} \cdot 4$ and $10 \cdot 0 \mathrm{mg}$. ions/l. Cultures were grown at $40^{\circ}$ and air at I l./min. was passed through them.

For the enzyme assays organisms were separated from the growth medium by centrifugation, washed with $\mathrm{NaCl}(0.85 \mathrm{~g}$. $/ 1$.) and resuspended in phosphate buffer $\left(\mathrm{KH}_{2} \mathrm{PO}_{4}, 2 \cdot 96 ; \mathrm{Na}_{2} \mathrm{HPO}_{4} \cdot \mathrm{I}_{2} \mathrm{H}_{2} \mathrm{O}, \mathrm{I} 6 \mathrm{~g} . / \mathrm{l} . ; \mathrm{pH} 7 \cdot \mathrm{I}\right)$ at a concentration of 0.5 to $\mathrm{I} \cdot 2 \mathrm{mg}$. dry weight $/ \mathrm{ml}$. (Using concentrations within this range in the assays as described below gave enzyme activities which were independent of the cell mass in the reaction mixtures.) When necessary the organisms were next disrupted in various ways: (i) ultrasonic treatment for I to $4 \mathrm{~min}$. ice-cold; (ii) adding $1 \% \mathrm{w} / \mathrm{v}$ of benzene and shaking for I to $5 \mathrm{~min}$. at $30^{\circ}$; (iii) incubating at $40^{\circ}$ for $24 \mathrm{hr}$ with $0.01 \%(\mathrm{w} / \mathrm{v})$ cetyltrimethylammonium bromide or $0.1 \%(w / v)$ sodium lauryl sulphate; (iv) using the lysozyme-sucrose-EDTA method of Birdsell \& Cota-Robles (1967). The fragments and the medium in which the organisms had been disrupted were assayed together.

Dehydrogenase activities were measured by the reduction of 2,3,5-triphenyltetrazolium chloride (TTC) in the presence of the appropriate substrate. One $\mathrm{ml}$. of suspension was added to five tubes containing I ml. carbon substrate under investigation and $2 \mathrm{ml}$. phosphate buffer $(\mathrm{pH} 7 \cdot 1)$. After $10 \mathrm{~min}$. incubation in a $40^{\circ}$ thermostat, I $\mathrm{ml}$. freshly prepared TTC solution (I $\mathrm{mg}$. $/ \mathrm{ml}$.) was added to each tube to start the reaction (the pre-incubation period gave maximum activity); at intervals tubes were removed from the water bath and $10 \mathrm{ml}$. acetone added to stop the reaction and extract the formazan. The tubes were then stoppered and after $24 \mathrm{hr}$ at room temperature (when all the debris had precipitated) the extinction was measured at $485 \mathrm{~m} \mu$. Since disturbance of the surface of the reaction mixture leads to changes in the reaction rate (Fred \& Knight, 1949) the use of separate tubes was preferable to withdrawing samples from a bulk reaction mixture. Plots of extinction against time were usually linear over the first $30 \mathrm{~min}$. and activities were always calculated from initial reaction rates, the amount of TTC reduced being obtained from a calibration curve relating it to extinction. This was obtained by reducing TTC solutions of known concentration with an excess of sodium hydrosulphite in the presence in turn of the various carbon sources used in the chemostat experiments. The amount of TTC reduced was independent of the carbon source and a linear relation existed between it and the extinction in the concentration range 0.015 to $\mathrm{I} \cdot 0 \mu \mathrm{M}$. A blank in which I ml. phosphate buffer replaced the carbon source in the assay was run in parallel and its value (which was taken as a measure of the endogenous enzyme activity) was subtracted from the observed activity to give the exogenous dehydrogenase activity. 
This is expressed as specific activity, i.e. $\mathrm{m} \mu$ moles TTC reduced/mg. dry weight organisms/min.

Activities of $\alpha$ - and $\beta$-glucosidase were determined by adding $5 \mathrm{ml}$. of $p$-nitrophenol ( $\alpha$ or $\beta$ )-D-glucopyranoside to $20 \mathrm{ml}$. suspension shaken at $40^{\circ}$. Five $\mathrm{ml}$. samples were withdrawn at intervals, $2 \mathrm{ml}$. $0.1 \mathrm{~N}-\mathrm{NaOH}$ added to stop the reaction, and the extinction determined at 400 to $420 \mathrm{~m} \mu$ with reference to a blank withdrawn at zero time. Initial rates were again determined and glucosidase specific activity is defined as $\mathrm{m} \mu$ moles $p$-nitrophenol liberated/mg. dry weight organisms/min.

\section{RESULTS}

Effect of $p H$ value, temperature, air flow rate and cell disruption

Changing the $\mathrm{pH}$ value of the medium or the temperature of growth had little effect on the steady state glucose dehydrogenase specific activities $\left(R_{G}\right)$ of organisms grown in glucose or $\mathrm{NH}_{4}{ }^{+}$-limited chemostats until the conditions were so adverso as to retard growth, viz. $\mathrm{pH}<5,>8$; temperature $>40^{\circ}$. $\mathbf{R}_{\mathrm{G}}$ also remained constant at air flow rates through the medium between 0 and $\mathrm{I} 1 . / \mathrm{min}$. The polysaccharide content of the organisms increased at low temperatures and the yield decreased at air flow rates below $0.81 . / \mathrm{min}$. Accordingly, a temperature of $40^{\circ}$ and an air flow rate of $\mathrm{I} 1 \mathrm{l} / \mathrm{min}$. were chosen as standard conditions since any slight uncontrolled variations would have a negligible effect.

Disruption of the organisms led to lower glucose dehydrogenase activities. The cetyltrimethylammonium bromide or sodium lauryl sulphate methods resulted in complete inactivation while ultrasonic treatment or treatment with benzene'or lysozyme and EDTA led to a 40 to $50 \%$ reduction. Adding FAD $\left(4 \times \mathrm{IO}^{-4} \mathrm{M}\right), \mathrm{NADP},\left(3 \times \mathrm{IO}^{-5} \mathrm{M}\right)$ or ATP $\left(4 \times 10^{-5} \mathrm{M}\right)$ to the assay mixtures had no effect. Glucosidase activities were also decreased by ultrasonic treatment; other methods of disruption were not tested. Since optimum levels of activity were desired, intact organisms were used throughout the experiments which follow.

\section{Dehydrogenase activities in carbon-limited systems}

Steady state glucose $\left(R_{G}\right)$, fructose $\left(R_{F}\right)$, maltose $\left(R_{M}\right)$ and sucrose $\left(R_{s}\right)$ dehydrogenase specific activities were determined in organisms growing in a wide variety of carbon-limited chemostats at dilution (growth) rates from $\mathrm{O}^{\cdot} \mathrm{I}$ to $\mathrm{I} \cdot \mathrm{o} \mathrm{hr}^{-1}$. Figure I $a$ shows that in the glucose-limited system $R_{G}, R_{F}, R_{M}$ and $R_{g}$ were equal and remained at a constant level at all except very low dilution rates. In all the other systems $R_{G}$, $\mathbf{R}_{\mathbf{F}}, \mathbf{R}_{\mathbf{M}}$ and $\mathbf{R}_{\mathrm{S}}$ differed depending on the carbon source in the medium, but since, with a few exceptions which will be pointed out presently, a similar independence of dilution rate occurred throughout, the constant levels only need be reported. These are listed in Table I, which shows that when sugars and related substances replaced glucose as the carbon source in the medium, $\mathbf{R}_{\mathrm{G}}$ remained high, only dropping below $80 \%$ of the control (glucose-limited) level in the D-arabinose system (Table I $a$ ). On the other hand, $R_{a}$ varied considerably and was often low when intermediates of the tricarboxylic acid cycle and related substances were the carbon sources (Table $\mathrm{I} b$ ). Moreover in this latter group of experiments a marked dependence of activity on dilution rate occured three times. In the malate-limited system this took the form of a linear decrease in $R_{0}$ as the dilution rate increased, while in the succinate- and 
citrate-limited systems maximum values occurred at dilution rates of 0.2 and $0.4 \mathrm{hr}^{-1}$ respectively. (The values given in Table $\mathbf{I} b$ for these systems are maximum values.) Organisms grown in gluconate and glycerol-limited systems had appreciable levels of $\mathrm{R}_{\mathrm{G}}$ (Table $\mathrm{I} c$ ). These substances are listed separately since the behaviour observed when they were used in $\mathrm{NH}_{4}{ }^{+}$-limited systems was atypical. This is dealt with in the next section.

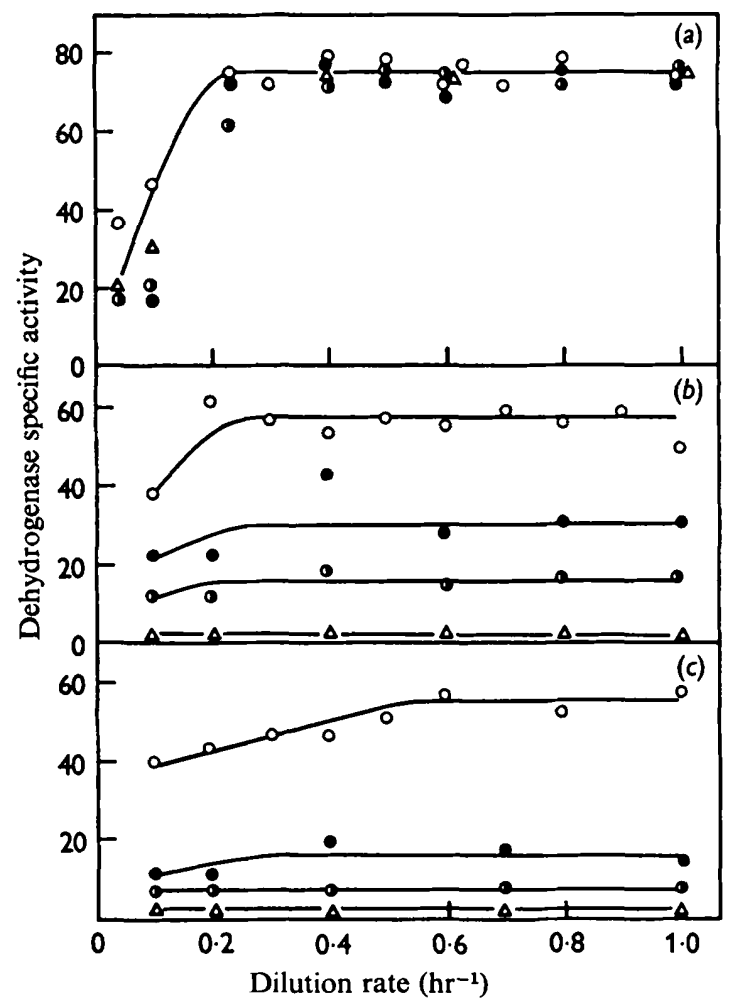

Fig. I. Steady state glucose $(O)$, fructose $(0)$, sucrose $(0)$ and maltose $(\triangle)$ dehydrogenase specific activities when glucose was the carbon source in the growth medium. (a) C-, (b) $\mathrm{K}^{+-}$and $(c) \mathrm{NH}_{4}^{+}$-limited chemostats.

The exact correspondence between $R_{G}, R_{F}, R_{M}$ and $R_{S}$ in the glucose-limited system was unique. The activities of other dehydrogenases in glucose-grown organisms varied considerably. For example, the specific activities of those acting on D-mannitol, lactose, L-arabinose, gluconate, L-glutamate, glycerol, pyruvate and lactate amounted to $75,23,19,17,14,10,7$ and $3 \%$ respectively of $R_{0}$. Moreover, in all the other systems listed in Table $\mathrm{I}$ in which significant levels of activity were detectable, $\mathbf{R}_{\sigma}$, $\mathbf{R}_{\mathrm{F}}, \mathbf{R}_{\mathbf{M}}$ and $\mathbf{R}_{\mathbf{s}}$, rather than being equal as in the glucose-limited system, usually fell in the order $\mathbf{R}_{\mathbf{G}}>\mathbf{R}_{\mathbf{F}}>\mathbf{R}_{\mathrm{M}}$ or $\mathbf{R}_{\mathrm{g}}$. $\mathbf{R}_{\mathrm{s}}$, however, was high in the fructose, maltose and raffinose-limited systems and in conditions in which fructose, maltose or sucrose had acted both as the carbon source in the growth medium and as substrate in the enzyme test, the level of activity of the relevant dehydrogenase (i.e. $R_{F}$ in fructosegrown, $R_{M}$ in maltose-grown organisms, etc.) increased considerably. This proved to be of general occurrence when the activities of other dehydrogenases such as those 
acting on D-mannitol, L-arabinose, lactose, malate, glycerol, pyruvate, lactate and L-glutamate were examined. Gluconate dehydrogenase, on the other hand, behaved more like glucose dehydrogenase. In the gluconate-limited system the gluconate dehydrogenase specific activity $\left(R_{G N}\right)$ of the organisms was $24 \cdot 6$ units. Here optimum activity might be expected since the carbon substrate performs the dual role just described. Like $\mathbf{R}_{\mathrm{G}}$, however, similar levels of activity occurred in many other systems and indeed in all the conditions in which $R_{G}$ was high, except the fructose-limited system, $\mathbf{R}_{\mathrm{Gx}}$ never varied by more than about $40 \%$, and when $\mathbf{R}_{\mathrm{G}}$ was low, $\mathbf{R}_{\mathrm{GN}}$ was also low.

Table I. Dehydrogenase activities in carbon-limited chemostats

\begin{tabular}{|c|c|c|c|c|c|}
\hline \multirow{2}{*}{$\begin{array}{l}\text { Carbon source } \\
\text { in medium }\end{array}$} & \multicolumn{5}{|c|}{ Relative activity* } \\
\hline & $\mathbf{R}_{\mathbf{G}}$ & $\mathbf{R}_{\mathbf{F}}$ & $\mathbf{R}_{\mathbf{s}}$ & $\mathbf{R}_{\mathbf{M}}$ & $\mathbf{R}_{\mathrm{GN}}$ \\
\hline (a) Glucose & $1 \cdot 00$ & $1 \cdot \infty$ & $1 \cdot \infty$ & $I \cdot \infty$ & 0.22 \\
\hline Fructose & 0.96 & 0.90 & 0.87 & 0.02 & 0.02 \\
\hline Sucrose & $I \cdot I 4$ & 0.59 & $I \cdot 12$ & 0.17 & 0.25 \\
\hline Maltose & 0.87 & 0.51 & 0.70 & 0.87 & 0.21 \\
\hline Xylose & $1 \cdot 20$ & $0.7 I$ & 0.04 & 0.29 & 0.28 \\
\hline D-mannitol & $1 \cdot 02$ & 0.80 & 0.21 & $0 \cdot 32$ & 0.35 \\
\hline Inositol & I.03 & 0.71 & 0.10 & $0 \cdot 30$ & $0.3 I$ \\
\hline Lactose & 0.80 & 0.30 & 0.03 & 0.04 & 0.25 \\
\hline Melibiose & $I \cdot \infty$ & 0.40 & 0.10 & 0.39 & $0.3 I$ \\
\hline Cellobiose & $\mathbf{I} \cdot \mathbf{O I}$ & 0.41 & $0 \cdot I I$ & 0.04 & 0.20 \\
\hline Raffinose & 0.86 & 0.50 & 0.71 & 0.29 & 0.24 \\
\hline L-arabinose & $1 \cdot \infty$ & 0.51 & 0.03 & 0.03 & 0.30 \\
\hline D-arabinose & 0.37 & 0.20 & 0 & 0 & 0.21 \\
\hline (b) Fumarate & $0.8 \mathrm{I}$ & 0.52 & 0.16 & 0.24 & 0.25 \\
\hline DL-glycerate & 0.64 & 0.38 & 0.03 & 0.20 & 0.21 \\
\hline Malate $\uparrow$ & 0.57 & 0.33 & 0.17 & 0.09 & 0.20 \\
\hline cis-Aconitate & 0.36 & 0.10 & 0 & 0 & 0.08 \\
\hline Citrate $†$ & O.I I & 0.05 & $0 \cdot 10$ & 0.06 & 0.07 \\
\hline Lactate & O. II I & 0 & 0 & 0 & 0.06 \\
\hline L-glutamate & 0.06 & 0.05 & 0 & 0 & 0.08 \\
\hline Succinate $†$ & $1 \cdot 00$ & 0.72 & 0.35 & 0.02 & 0.37 \\
\hline Pyruvate & 0 & 0 & 0 & 0 & 0.12 \\
\hline Malonate & 0 & 0 & 0 & 0 & 0.03 \\
\hline Acetate & 0 & 0 & 0 & 0 & 0.12 \\
\hline (c) Gluconate & 0.53 & 0.20 & 0.18 & 0 & 0.34 \\
\hline Glycerol & 0.67 & 0.64 & 0.17 & 0.32 & 0.23 \\
\hline
\end{tabular}

* The glucose dehydrogenase specific activity of intact organisms grown in glucose-limited conditions (i.e. $75.0 \mathrm{~m} \mu \mathrm{moles}$ TTC reduced/mg. dry weight organisms $/ \mathrm{min}$.) is taken as $\mathrm{I} \cdot 0$ and the other activities expressed relative to it. $\mathbf{R}_{G}, \mathbf{R}_{\mathbf{F}}, \mathbf{R}_{\mathbf{S}}, \mathbf{R}_{\mathbf{M}}$ and $\mathbf{R}_{\mathbf{G N}}$ denote the levels of activity obtained using glucose, fructose, sucrose, maltose and gluconate respectively as substrates in the enzyme tests. Except where indicated $(\dagger)$ these levels applied at all dilution rates from 0.3 to $\mathrm{I} \cdot 0 \mathrm{hr}^{-1}$.

$\dagger$ Maximum values (seo text).

\section{Dehydrogenase activities in conditions other than C-limitation}

The range of dilution rates from $0 \cdot \mathrm{I}$ to $\mathrm{I} \cdot \mathrm{O} \mathrm{hr}^{-1}$ was again used, and when glucose was the carbon source $\mathbf{R}_{G}$, although lower than in C-limitation, still ran at a high level in $\mathrm{K}^{+}, \mathrm{NH}_{4}^{+}, \mathrm{Mg}^{2+}$ and $\mathrm{SO}_{4}{ }^{2-}$-limited systems, the constant levels being 76,73 , 72 and $78 \%$ respectively of that in the glucose-limited system, but in the $\mathrm{PO}_{4}{ }^{3}$-limited conditions it was only $52 \%$. Except in the $\mathrm{K}^{+}$-limited system, however, the range of dilution rates over which $\mathbf{R}_{G}$ was independent of the dilution rate was shorter. 
Figures $\mathrm{I} b, c$ show the results obtained in the $\mathrm{K}^{+}$and $\mathrm{NH}_{4}^{+}$-limited systems as typical examples, and should be compared with Fig. I $a$. Figures $\mathrm{I} b, c$ also show that $\mathbf{R}_{F}, \mathbf{R}_{M}$ and $R_{8}$ were again no longer equal to $R_{G}$, but decreased in the order $R_{G}>R_{F}>R_{g}$ $>\mathbf{R}_{\mathrm{M}}$. This also occurred in the other nutrient-limited systems, the over-all behaviour once more emphasizing the uniqueness of the equal levels of $R_{G}, R_{F}, R_{B}$ and $R_{M}$ in the glucose-limited system.

Essentially similar results were obtained when fructose, sucrose or maltose were used in turn as carbon sources. Only $\mathrm{K}^{+}$and $\mathrm{NH}_{4}{ }^{+}$-limited systems were studied, and again $R_{G}, R_{F}, R_{B}$ and $R_{M}$ were lower than in the corresponding $C$-limited systems, even in the special conditions pertaining when the carbon source in the medium and the substrate in the enzyme test were identical. Here the activity of the relevant dehydrogenase increased to almost that of the now lower level of $R_{0}$. For example, in sucrose-containing systems, $R_{G}, R_{F}, R_{B}$ and $R_{M}$ were $83.5,43.0,82.2$ and 12.3 units respectively in C-limitation, $70 \cdot 0,44 \cdot 2,55 \cdot 2$ and 2.5 in $\mathrm{K}^{+}$limitation, and $52 \cdot 6,41 \cdot 7$, 50.4 and 2.5 in $\mathrm{NH}_{4}{ }^{+}$-limitation, the order $\mathbf{R}_{G}>\mathbf{R}_{\mathrm{B}}>\mathbf{R}_{\mathrm{F}}>\mathbf{R}_{\mathrm{M}}$ being preserved throughout. Similarly $R_{F}$ in fructose-limited conditions and $\mathbf{R}_{\mathbf{M}}$ in maltose-limited conditions were higher than any other except $\mathbf{R}_{\mathbf{a}}$.

Table 2. Glucosidase activities in various nutrient-limited systems

$\begin{gathered}\text { Nutrient } \\ \text { controlling } \\ \text { growth }\end{gathered} \quad \overbrace{\alpha \text {-Glucosidase }}^{\beta \text {-Glucosidase }}$
Relative activity*

(a) Various carbon sources, $\mathrm{NH}_{4}^{+}$as nitrogen source

$\begin{array}{lll}\text { Glucose } & 0.22 & 0.14 \\ \text { Fructose } & 0.32 & 0.14 \\ \text { Sucrose } & 0.11 & 0.20 \\ \text { Maltose } & 1.00 & 0.08 \\ \text { Cellobiose } & 0.33 & \mathbf{1 . 0 0} \\ \text { Melibiose } & 0.32 & 0.56 \\ \text { Lactose } & 0.27 & 0.15\end{array}$

(b) Glucose as carbon source, $\mathrm{NH}_{4}{ }^{+}$as nitrogen source

$\begin{array}{llc}\mathrm{C} & 0.22 & 0.14 \\ \mathrm{~N} & 0.08 & 0.04 \\ \mathrm{~K}^{+} & 0.06 & - \\ \mathrm{Mg}^{2+} & 0.15 & - \\ \mathrm{SO}_{4}{ }^{2-} & 0.12 & - \\ \mathrm{PO}_{4}{ }^{8-} & 0.09 & -\end{array}$

(c) Glucose as carbon source, $\mathrm{NO}_{2}^{-}$as nitrogen source

$\begin{array}{lll}\mathrm{C} & 0.24 & 0.72 \\ \mathrm{~N} & 0.13 & 0.16\end{array}$

(d) Glucose as carbon source, $\mathrm{NO}_{3}{ }^{-}$as nitrogen source

$\begin{array}{lll}\mathrm{C} & 0.13 & 0.01 \\ \mathrm{~N} & 0.30 & 0.01\end{array}$

* The $\alpha$-glucosidase specific activity (i.e. $1.96 \mathrm{~m} \mu$ moles $p$-nitrophenol liberated/mg. dry weight organisms/min.) of intact organisms grown in the maltose-limited system is taken as $1 \cdot 0$ and the other $\alpha$-glucosidase activities expressed relative to it. Similarly for $\beta$-glucosidases the specific activity obtained in cellobiose-limited conditions (i.e. $36.8 \mathrm{~m} \mu$ moles $p$-nitrophenol liberated/mg. dry weight organisms/min.) is taken as $1 \cdot 0$. Dilution rate $0.4 \mathrm{hr}^{-1}$ throughout.

In sharp contrast, the gluconate dehydrogenase specific activity $\left(R_{\mathbf{G N}}\right)$ of gluconategrown organisms and the glycerol dehydrogenase specific activity $\left(\mathrm{R}_{\mathrm{aL}}\right)$ of glycerolgrown organisms were approximately twice as high in $\mathrm{NH}_{\mathbf{4}}{ }^{+}$-limitation compared to 
C-limitation (i.e. C-limitation $\mathrm{R}_{\mathrm{GN}} 24 \cdot 6, \mathbf{R}_{\mathrm{GL}} 22 \cdot 0$; $\mathrm{NH}_{4}{ }^{+}$-limitation $\mathrm{R}_{\mathrm{GN}} 47 \cdot 7, \mathrm{R}_{\mathrm{GL}}$ 46.6). The activities of the other dehydrogenases were also significantly higher except for $\mathbf{R}_{\mathbf{s}}$ in the gluconate system and $\mathbf{R}_{\mathbf{M}}$ in the glycerol system which conformed to the more usual pattern. Other nutrient-limited systems were not investigated.

\section{$\alpha$ - and $\beta$-glucosidase specific activities}

In C-limited conditions in which various sugars were the carbon sources the highest $\alpha$-glucosidase activity was observed in organisms grown in the maltose (i.e. Glc $p$ $\alpha_{\mathrm{I}} \rightarrow 4 \mathrm{Glc}$ )-limited system. Melibiose (i.e. Gal p $\alpha \mathrm{I} \rightarrow 6 \mathrm{Glc}$ ) induced little activity and low levels also occurred in glucose, fructose, lactose and sucrose-grown cells, particularly in the last (Table $2 a$ ). A dilution rate of $0.4 \mathrm{hr}^{-1}$ was used in these experiments since more detailed investigations of glucose and maltose-limited systems had shown that, like dehydrogenase activities in general, $\alpha$-glucosidase activities were relatively independent of the dilution rate over a wide range. Unlike dehydrogenases, however, the activity increased progressively, rather than decreasing, as the dilution rate was reduced below $0.3 \mathrm{hr}^{-1}$. Indeed, in the maltose-limited system the levels at rates of 0.2 and $0.1 \mathrm{hr}^{-1}$ respectively were 9.9 and $20.0 \%$ higher than the constant level (compare Fig. I).

Although low in $\alpha$-glucosidase, organisms grown in melibiose-limited conditions had a relatively high $\beta$-glucosidase activity. This was some 50 to $60 \%$ of the highest level observed, i.e. in the cellobiose (Glc p $\beta_{\mathrm{I}} \rightarrow 4 \mathrm{Glc}$ )-limited system, while in the other $\mathrm{C}$-limited systems the activity ranged from about one-third of this optimum level in sucrose-grown organisms to about one-tenth in maltose-grown organisms (Table $2 a$ ). Table $2 b$ shows the lower levels of both glucosidases obtained in $\mathrm{NH}_{4}{ }^{+}-$ limitation compared to $\mathrm{C}$-limitation when glucose was the carbon source. This also occurred when $\mathrm{NO}_{2}^{-}$replaced $\mathrm{NH}_{4}{ }^{+}$as the nitrogen source in the medium but in addition the level of activity of $\beta$-glucosidase (but not $\alpha$-glucosidase) increased considerably in both $\mathrm{C}$ and $\mathrm{N}$-limitation (Table $2 c$ ). Using $\mathrm{NO}_{3}{ }^{-}$, however, led to a drop in $\beta$-glucosidase activity (Table $2 d$ ).

\section{DISCUSSION}

Clarke et al. (1968) found that the specific activity of an inducible amidase in Pseudomonas aeruginosa passed through a sharp maximum at a dilution rate of 0.30 to $0.35 \mathrm{hr}^{-1}$ while that of a fully constitutive mutant decreased with increasing dilution rate. On the other hand Wright \& Lockhart (1965) reported an increase in the glucose-6-phosphate dehydrogenase activity of Escherichia coli $\mathrm{K}$ I 2 with increasing dilution rate. We rarely observed these patterns of behaviour with glucose dehydrogenase. Instead, the specific activity was almost invariably relatively independent of the dilution rate and this, together with the small variations which occurred when many sugars and related substances replaced glucose as the carbon source in the medium (Table I $a$ ), could be cited as evidence for a constitutive glucose dehydrogenase system. However the precise differentiation between 'constitutivity' and 'inducibility' can present difficulties (see, for example, Liss, Horwitz \& Kaplan, I962; Moses \& Sharp, 1968) and conditions do exist in which the glucose dehydrogenase specific activity is low or even undetectable (Table $\mathrm{I} b$ ). Moreover even when it remained high over most of the range of dilution rates it decreased at very low rates, and when the 
carbon source in the medium was present in excess of requirement, as occurs in all conditions of nutrient-limitation other than C-limitation, the levels of activity were lower throughout.

Apart from gluconate dehydrogenase, which behaved in general like glucose dehydrogenase, the other dehydrogenases, although also relatively independent of the dilution rate, were much more affected by the nature of the rate-limiting nutrient and appeared to increase in activity just when required. This is the behaviour of inducible dehydrogenase systems and is in agreement with the conclusions drawn by others from batch culture experiments using a variety of organisms (see Lin, 1961; Hayashi, Hayash \& Unemoto, I966; Henning, Dietrich \& Deppe, I968). However, Liss et al. (1962) and Tanaka, Lerner \& Lin (1967) concluded that Klebsiella aerogenes (ATCC 8724) dissimulated mannitol via a constitutive mannitol-I-phosphate dehydrogenase. Mannitolgrown organisms had an increased level of this enzyme but in contrast to our strain showed no mannitol dehydrogenase activity. Schaefler \& Schenkein (1968) and Fox \& Wilson (1968) envisage that phosphorylation also precedes the hydrolysis of $\beta$-glucosides in Enterobacteriaceae, in general, since the liberation of $p$-nitrophenol from phosphorylated $p$-nitrophenol $\beta$-D-glucosides was more rapid than from the nonphosphorylated substrates. We have used the latter throughout our assays for $\alpha$ - and $\beta$-glucosidases and these enzymes also increased in activity just when required, although the induction of $\beta$-glucosidase by melibiose ( $\mathrm{Gal} \mathrm{p} \alpha \mathrm{l} \rightarrow 6 \mathrm{Glc}$ ) is exceptional in this respect. Melibiose also induces $\beta$-galactosidase (Monod, Cohen-Bazire \& Cohn, 1951).

Variations in the metabolism of glucose by different strains of Klebsiella aerogenes have also been reported. Forget (1968) estimated, from tests carried out after 20 to $24 \mathrm{hr}$ of growth in aerobic batch culture, that the Embden-Meyerhof and the hexosemonophosphate shunt pathways participated to the extent of 60 and $40 \%$ respectively in strain L I I I-I. In contrast, in $K$. aerogenes (PRL-R 3) Dalby \& Blackwood (I955) obtained evidence for the operation of a non-phosphorylated Entner-Doudoroff type of metabolic pathway, in which glucose is dehydrogenated to gluconate by glucose dehydrogenase. In our experiments the correlation between a high level of glucose dehydrogenase activity and an appreciable gluconate dehydrogenase activity suggests that a similar pathway exists in $K$. aerogenes ( $\mathrm{NCIB} 4 \mathrm{I} 8$ ) and an approximate calculation based on the transfer of electrons to TTC shows that under optimum conditions $40 \%$ of the glucose in the medium could be degraded by this route, the remainder presumably being metabolized by more usual routes, although no direct evidence of those involved is available at present. Similar considerations could also apply in the other chemostat systems in which the activity of the relevant dehydrogenase is high although variations in some of the steps in the reaction sequences are inevitable. In particular, disaccharides could either be dehydrogenated directly (Gunsalus, Horecker \& Wood, 1955) or else hydrolysed before further degradation, and in some circumstances this hydrolysis might conceivably occur during the dehydrogenase tests themselves. For example, organisms from the maltose-limited system have a high $\alpha$-glucosidase activity and since in the enzyme tests bacteria and substrate were incubated together before adding the TTC, it is quite possible that part at least of the estimated maltose dehydrogenase activity is due to the action of glucose dehydrogenase. However, in other systems such as the $\mathrm{NH}_{4}{ }^{+}$and $\mathrm{K}^{+}$-limited maltose systems, the $\alpha$-glucosidase activity of the organisms is low and the dehydrogenation of the substrate itself would be measured. 
Definite proof of the presence of a specific maltose dehydrogenase system, and of the others also, requires the isolation of the enzymes themselves and for this a gentler method of cell rupture is desirable since the use of any of a variety of standard techniques led to marked inactivation. This also precluded any assessment of permeation effects by a comparison of the activities of intact and disrupted organisms. Nevertheless, incubation of the intact organisms with substrate prior to adding the TTC resulted in maximum activity and on its addition the response was linear although when the activities were low this was preceded by a lag. Grant \& Hinshelwood (1964) concluded that permeation of the substrate was not the rate-limiting step with 'fully mobilized' dehydrogenases in our strain of Klebsiella aerogenes grown in batch culture, although it might be with 'non-mobilized' dehydrogenases. As in our experiments they observed a decline in activity of the former on ultrasonic treatment of the bacteria, whereas the low levels of activity of the 'non-mobilized' enzymes increased some $50 \%$ before decreasing. We have not investigated this latter aspect since, being obliged to use intact organisms when the activities were high, a standard technique was used throughout. Effects of this magnitude, however, do not in themselves account for the low levels of activity. The precise conditions of growth are of greater importance.

\section{REFERENCES}

Birdsell, D. C. \& Cota-Robles, E. H. (1967). Production and ultrastructure of lysozyme and ethylenediaminetetracetate-lysozyme spheroplasts of Escherichia coli. J. Bact. 93, 427.

Clarke, P. H., Houldsworth, M. A. \& Lilly, M. D. (1968). Catabolite repression and the induction of amidase synthesis by Pseudomonas aeruginosa 8602. J. gen. Microbiol. 51, 225.

Dalby, A. \& BlACKwOOD, A. C. (1955). Oxidation of sugars by an enzyme preparation from Aerobacter aerogenes. Can. J. Microbiol. 1, 733.

Dean, A. C. R. \& Rogers, P. L. (1967). The cell size and macromolecular composition of Aerobacter aerogenes in various systems of continuous culture. Biochim. biophys. Acta 148, 267.

Forget, P. (1968). Recherches sur le métabolisme du glucose chez les bactéries dénitrificantes. 1. Aerobacter aerogenes. Annls Inst. Pasteur, Paris $115,181$.

Fox, C. F. \& Wilson, G. (1968). The role of a phosphoenolpyruvate-dependent kinase system in B-glucoside catabolism in Escherichia coli. Proc. natn. Acad. Sci. U.S.A. 59, 988.

Fred, R. B. \& KNIGHT, S. G. (1949). The reduction of 2,3,5-triphenyl-tetrazolium chloride by Penicillium chrysogenum. Science, N.Y. 109, 169.

Grant, D. J. W. \& HinshelwoOd, C. (1964). Studies of the enzyme activity of Bact. lactis aerogenes (Aerobacter aerogenes). I. The effects of cellular disruption on the activities of some typical enzymes. Proc. $R$. Soc. B 160, 25.

Gunsalus, I. C., Horecker, B. L. \& WoOd, W. A. (1955). Pathways of carbohydrate metabolism in micro-organisms. Bact. Rev. 19, 79.

Hamlin, B. T., NG, F. M.-W. \& Dawes, E. A. (1967). Regulation of enzymes of glucose metabolism in Pseudomonas aeruginosa by citrate. In Microbial Physiology and Continuous Culture. Ed. E. O. Powell, C. G. T. Evans, R. E. Strange and D. W. Tempest, p. 2 I I. London: H.M.S.O.

Hayashi, M., Hayashi, M. \& Unemoto, T. (1966). The presence of D-malate dehydrogenase (Dmalate: NAD oxidoreductase) in Serratia marcescens. Biochim. biophys. Acta 122, 374.

Henning, U., Dietrich, J. \& DePpe, G. (I968). Regulation of the synthesis of Escherichia coli pyruvate dehydrogenase. Biochem. J. I06, 25 P.

LIN, E. C. C. (1961). An inducible D-arabitol dehydrogenase from Aerobacter aerogenes. J. biol. Chem. 236, 31 .

Liss, M., HoRwITZ, S. B. \& KAPLAN, N. O. (1962). D-mannitol-I-phosphate dehydrogenase and D-sorbitol-1-phosphate dehydrogenase in Aeorbacter aerogenes. J. biol. Chem. 237, I342.

MÁLEK, I. (1969). Proceedings 4th International Symposium on continuous culture of micro-organisms Prague, 1968. Folio microbiol., Praha (in the Press). 
Monod, J., Cohen-Bazire, G. \& Cohn, M. (I95I). Sur la biosynthèse de la $\beta$-galactosidase (lactase) chez Escherichia coli. La spécificité de l'induction. Biochim. biophys. Acta 7, 585.

Moses, V. \& Sharp, P. B. (I968). Studies on the regulation of glucose-metabolizing enzymes in Bacillus subtilis. J. gen. Microbiol. 52, 391.

PIRT, S. J. (I967). Steady state conditions for synthesis of exocellular products. In Microbial Physiology and Continuous Culture. Ed. E. O. Powell, C. G. T. Evans, R. E. Strange and D. W. Tempest, p. 162. London: H.M.S.O.

SChAefler, S. \& SchenkeIn, I. (1968). $\beta$-glucoside permeases and phospho- $\beta$-glucosidases in Aerobacter aerogenes . Relationship with cryptic phospho- $\beta$-glucosidases in Enterobacteriaceae. Proc. natn. Acad. Sci. U.S.A. 59, 285.

TANAKA, S., LeRner, S. A. \& Lin, E. C. C. (1967). Replacement of a phosphoenolpyruvate-dependent phosphotransferase by a nicotinamide adenine dinucleotide-linked dehydrogenase for the utilization of mannitol. J. Bact. 93, 642 .

TEMPEST, D. W. \& HeRBerT, D. (1965). Effect of dilution rate and growth-limiting substrate on the metabolic activity of Torula utilis. J. gen. Microbiol. 4r, 143.

WRIGHT, D. N. \& LockHART, W. R. (1965). Effects of growth rate and limiting substrate on glucose metabolism in Escherichia coli. J. Bact. 89, 1082. 